\title{
Effect of a 2-HP- $\beta$-Cyclodextrin Formulation on the Biological Transport and Delivery of Chemotherapeutic PLGA Nanoparticles
}

\author{
Kangyu Zheng ${ }^{1,2, *}$ \\ Zeju Huang ${ }^{1,2}$ \\ Jiaying Huang ${ }^{1,2}$ \\ Xiangmei $\mathrm{Liu}^{3, *}$ \\ Junfeng Ban $\mathbb{D}^{1,2, *}$ \\ Xin Huang ${ }^{1,2}$ \\ Haosen Luo $\mathbb{D}^{1,2}$ \\ Zhicong Chen ${ }^{1,2}$ \\ Qingchun Xie ${ }^{1,2}$ \\ Yanzhong Chen ${ }^{1,2}$ \\ Zhufen $\mathrm{Lu}^{\mathrm{I}, 2}$
}

'Guangdong Provincial Key Laboratory of Advanced Drug Delivery Systems,

Guangdong Pharmaceutical University,

Guangzhou, People's Republic of China;

${ }^{2}$ Guangdong Provincial Engineering

Center of Topical Precision Drug

Delivery System, Center for Drug

Research and Development, Guangdong

Pharmaceutical University, Guangzhou,

People's Republic of China; ${ }^{3}$ Guangzhou

Quality Supervision and Testing Institute,

Guangzhou, People's Republic of China

*These authors contributed equally to this work

Correspondence: Yanzhong Chen; Zhufen Lu

Guangdong Provincial Key Laboratory of Advanced Drug Delivery Systems,

Guangdong Pharmaceutical University,

Guangzhou, 510006, People's Republic of

China

Tel +862039352506

Email doctor.c@163.com; luzhufen@163.

com
Background: The aim of this work was to develop a novel and feasible modification strategy by utilizing the supramolecular effect of 2-hydroxypropyl-beta-cyclodextrin (2-HP- $\beta$-CD) for enhancing the biological transport efficiency of paclitaxel (PTX)-loaded poly(lactide-co-glycolide) (PLGA) nanoparticles.

Methods: PTX-loaded 2-HP- $\beta$-CD-modified PLGA nanoparticles (2-HP- $\beta-C D / P L G A ~ N P s)$ were prepared using the modified emulsion method. Nano-characteristics, drug release behavior, in vitro cytotoxicity, cellular uptake profiles and in vivo bio-behavior of the nanoparticles were then characterized.

Results: Compared with the plain PLGA NPs, 2-HP- $\beta$-CD/PLGA NPs exhibited smaller particle sizes $(151.03 \pm 1.36 \mathrm{~nm})$, increased entrapment efficiency $(\sim 49.12 \%$ increase) and sustained drug release. When added to A549 human lung cancer cells, compared with PLGA NPs, 2-HP- $\beta$-CD/PLGA NPs exhibited higher cytotoxicity in MTT assays and improved cellular uptake efficiency. Pharmacokinetic analysis showed that the AUC value of 2-HP- $\beta$ CD/PLGA NPs was 2.4-fold higher than commercial Taxol ${ }^{\circledR}$ and 1.7-fold higher than plain

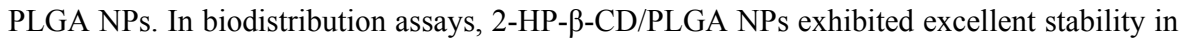
the circulation.

Conclusion: The results of this study suggest that the formulation that contains $2-\mathrm{HP}-\beta-\mathrm{CD}$ can prolong PTX release, enhance drug transport efficiency and serve as a potential tumor targeting system for PTX.

Keywords: PLGA nanoparticle, 2-hydroxypropyl- $\beta$-cyclodextrin, sustained release, $\mathrm{pH}-$ responsive, long-circulating, cancer treatment

\section{Background}

When an antitumor nanomedicine is administered in the body, it undergoes 5 main steps, including blood circulation, tumor accumulation, deep penetration, cell internalization, and drug release to effectively kill tumor cells. Any hindrance in this process will affect the overall therapeutic effect of the drug. ${ }^{1,2}$ Abnormal tumor blood vessels, high interstitial pressure, large tumor cell density, and dense extracellular matrix often hinder the penetration of nanomedicine into the tumor sites. ${ }^{3-5}$ In tumor tissues, as new blood vessels are generated to supply excess nutrients and oxygen to cells, the permeability of tumor capillaries increases; therefore, the plasma proteins and other macromolecules leach out, causing lymphatic circulation, and thus, interstitial hydraulic pressure is elevated, ${ }^{6,7}$ causing chaotic arrangement of capillaries and distortion of structure. ${ }^{8}$ Also, increased levels of proteoglycan, 
growth factors, and hyaluronic acid in the extracellular matrix of tumors, increased collagen levels, ${ }^{9}$ increased lysine oxidase content, and enhanced covalent cross-linking ability with collagen, ${ }^{10,11}$ etc., cause accumulation of drugs in the marginal tissues of the tumor; the drug spreads slowly and faces difficulties to reach the central part, ${ }^{12-15}$ which hinders drug delivery. ${ }^{16,17}$ Recently, the anti-tumor nanomedicine research is focusing on understanding the mechanism of nanomedicine's penetration into the capillary wall to reach the surface layer of tumor tissue by penetrating the complex microenvironment matrix of the tumor to reach the deep layer of the tumor under high interstitial pressure. ${ }^{17}$ However, it remains necessary to develop new strategies that can simultaneously enhance the tumor targeting and biological transport abilities of therapeutic agents. In this study, we aimed to adjust the size and properties of PLGA nanoparticles delivery system to enhance their penetration at the tumor site and accumulation near the tumor capillaries for their effective entry to the tumor cells. The antitumor efficacy of the formulations was assessed in vitro with cancer cell and in vivo with animals. To investigate the multi-factor influence on bioavailability, the relevance between the physicochemical (size, morphology, dissolution behavior et al) and biochemical properties (cytotoxicity, cellular uptake et al) of NPs was analyzed in detail.

\section{Materials and Methods}

\section{Materials}

Paclitaxel (PTX) was purchased from InnoChem Science \& Technology Co., Ltd. (Beijing, People's Republic of China); Free paclitaxel (commercial Taxol ${ }^{\mathbb{R}}$ ) was purchased from Mei Lai Pharmaceutical Co., Ltd. (Chongqing, People's Republic of China); PLGA (LA:GA =50:50, $\mathrm{MW}=10 \mathrm{k}, 20 \mathrm{k}$ and $30 \mathrm{k}$, ester terminated) was purchased from Dai Gang Bioengineering Co., Ltd. (Jinan, People's Republic of China); Polyvinyl alcohol (PVA) was supplied by Cola International Trade Co., Ltd. (Shanghai, People's Republic of China); 2-hydroxypropyl- $\beta$-cyclodextrin (2-HP- $\beta-C D)$ was a gift from Qian Hui Biotechnology Co., Ltd. (Zibo, People's Republic of China); RhodamineB was purchased from Da Mao Chemical Reagent Co., Ltd. (Tianjin, People's Republic of China); 3-(4,5-dimethylthiazol-2-yl)-2,5-diphenyltetrazolium bromide (MTT) was purchased from Sigma-Aldrich Co. (St Louis, MO, USA). All other reagents were of the highest commercial grade available. Human lung cancer cell lines A549 was purchased by the American Type Culture Collection (ATCC, Manassas, VA, USA).

\section{Water-Oil -Water Emulsion Solvent Evaporation Method}

PTX-PLGA NPs were prepared using a water-oil-water (W/OW) emulsion solvent evaporation method. ${ }^{18,19}$ Briefly, $2 \mathrm{mg}$ of PTX and $60 \mathrm{mg}$ of PLGA were dissolved in $3 \mathrm{~mL}$ of acetone: ethyl alcohol (8: 2, v/v) solution. The organic phase of the solvent was then slowly injected into $20 \mathrm{~mL} \mathrm{2 \%}$ PVA solution with ultrasonication $(150 \mathrm{kHz}$ of energy output, JY88-IIN, Scientz Biotechnology Co., Ltd, People's Republic of China) for $10 \mathrm{~min}$. The emulsion solution was stirred overnight to evaporate the organic solvent and the NPs were centrifuged at $15,000 \mathrm{rpm}\left(4^{\circ}\right.$ C) for $30 \mathrm{~min}$ (5424R, Eppendorf, Germany) and washed three times in $20 \mathrm{~mL}$ of distilled water to remove unencapsulated drug and PVA emulsifier. To investigate the effects of different PLGA molecular weights on particle size, zeta potentials and the encapsulation efficiency of the nanoparticles, drug-loaded NPs of different molecular weights $(10 \mathrm{k}, 20 \mathrm{k}$ and $30 \mathrm{k})$ were prepared and surveyed.

For preparation of $2-\mathrm{HP}-\beta-\mathrm{CD} / \mathrm{PLGA}$ NPs,a mixed solution consisting of $2-\mathrm{HP}-\beta-\mathrm{CD}(2 \%, \mathrm{w} / \mathrm{v}$, in $2 \%$ PVA in distilled water) was used as the dispersing phase for the emulsion solvent diffusion process. Fluorescence-labeled NPs were prepared by the replacement of PTX with $2 \mathrm{mg}$ of rhodamine-B (RDM). All the formulations as shown in Table 1.

\section{Nanoparticle Characterization}

\section{Particle Size and Zeta Potential}

The hydrodynamic size and zeta potential of the PLGA NPs and 2-HP- $\beta$-CD/PLGA NPs were measured by dynamic light scattering (DLS; Delsa nano C, Beckman Coulter Inc., California, USA). The NPs were suspended in distilled water prior to experiments and multiple runs $(>3)$ were performed to avoid erroneous results.

\section{Encapsulation Efficiency}

The encapsulation efficiency of the NPs was determined by Sephadex Chromatography. Briefly, $0.5 \mathrm{~mL}$ of the sample was loaded onto a Sephadex G-50 column $(1.5 \mathrm{~cm} \times 15 \mathrm{~cm})$ to which $30 \mathrm{~mL}$ of sterile water and $30 \mathrm{~mL}$ of $5 \%$ sodium dodecyl sulfate (SDS) were used for elution. The drug EE (\%) of PTX-loaded NPs was determined by HPLC and calculated using the following equation: 
Table I Formulation Composition

\begin{tabular}{|c|c|c|c|c|}
\hline Formulation & $\begin{array}{l}\text { PTX-Loaded } \\
\text { PLGA NPs }\end{array}$ & $\begin{array}{c}\text { PTX-Loaded 2-HP- } \beta-C D / \\
\text { PLGA NPs }{ }^{a}\end{array}$ & $\begin{array}{l}\text { Fluorescence-Labeled } \\
\text { PLGA NPs }\end{array}$ & 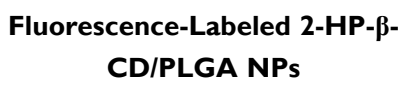 \\
\hline Paclitaxel (w/v) & $0.0087 \%$ & $0.0087 \%$ & - & - \\
\hline PLGA (w/v) & $0.26 \%$ & $0.26 \%$ & $0.26 \%$ & $0.26 \%$ \\
\hline Acetone: Ethyl alcohol & $8 / 2$ & $8 / 2$ & $8 / 2$ & $8 / 2$ \\
\hline Solution $(v / v)$ & & & & \\
\hline PVA (w/v) & $2 \%$ & $2 \%$ & $2 \%$ & $2 \%$ \\
\hline $2-H P-\beta-C D(w / v)$ & - & $2 \%$ & - & $2 \%$ \\
\hline Rhodamine-B & - & - & $0.0087 \%$ & $0.0087 \%$ \\
\hline
\end{tabular}

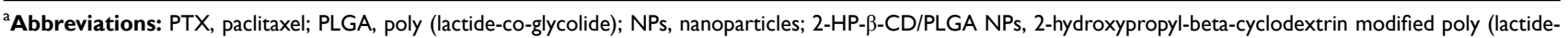
co-glycolide); PDI, polydispersity index.

$$
E E(\%)=\frac{\text { the amount of PTX in the NPs }}{\text { the amount of PTX }} \times 100 \%
$$

The HPLC analysis was performed using Waters (e2695 HPLC system, Waters, USA) HPLC equipment, fitted with a Kromasil 100-5-C18 column $(4.6 \times 250 \mathrm{~mm}, \mathrm{dp}=5 \mu \mathrm{m})$. The mobile phase consisted of a mixture of methyl alcohol and purified water (65:35). All HPLC experiments were carried out in the isocratic mode. The injection volume was $20 \mu \mathrm{L}$ with a flow rate of $1 \mathrm{~mL} / \mathrm{min}$. The column temperature was maintained at $25^{\circ} \mathrm{C}$, and elution was monitored at $227 \mathrm{~nm}$.

\section{Surface Morphology}

The nanoparticles were characterized through the assessment of their morphology via transmission electron microscopy (TEM; JEM-1400, JEOL Co., Tokyo, Japan). Samples for TEM observations were prepared through the drop-wise addition of diluted sample solutions onto a copper grid coated with a carbon membrane. The grid was then dried, dyed with $2 \%$ phosphotungstic acid and air-dried. The surface morphology of PLGA and 2-HP- $\beta$ CD/PLGA NPs was then examined by TEM.

\section{X-Ray Diffraction Analysis}

X-ray diffraction analysis (D8-Advance, Bruker Co., Germany) was used to determine the crystalline state of PTX in different PLGA and 2-HP- $\beta$-CD/PLGA NPs. These analyses were carried out using copper targets that were adjusted to a tube pressure of $40 \mathrm{Kv}$. The tube flow was set to $40 \mathrm{~mA}$ and scanning diffraction peaks between $5^{\circ}$ and $40^{\circ}$ at $2 \theta$ were recorded.

\section{Fourier Transform Infrared Spectroscopy Analysis}

Fourier transform infrared (FT-IR) spectroscopy analysis of the PLGA NPs and 2-HP- $\beta$-CD/PLGA NPs were recorded on a FT-IR spectrophotometer (Spectrum 100, PerkinElmer Co., Boston, USA) using $\mathrm{KBr}$.

\section{In vitro Release Profiles}

The $\mathrm{pH}$ of the blood stream is $\sim 7.4$ compared to $\sim 6.8$ in the tumor extracellular microenvironment and $\sim 5.0$ in late endosomes/lysosomes. ${ }^{20,21}$ To verify the $\mathrm{pH}$-dependent kinetics of drug release, PLGA and 2-HP- $\beta-\mathrm{CD} / \mathrm{PLGA}$ NPs were incubated in $2 \%$ SDS solutions at $\mathrm{pH} 7.4, \mathrm{pH} 6.8$ or $\mathrm{pH}$ 5.0 at $37^{\circ} \mathrm{C}$ for $72 \mathrm{~h}$ and the release of PTX was monitored using HPLC.

\section{In vitro Cytotoxicity}

The cytotoxicity of nanoparticles was evaluated by MTT assays in A549 cells. Cells were seeded in a 96-well plate (4000 cells/well) for $24 \mathrm{~h}$ prior to analysis and free PTX, PLGA and 2-HP- $\beta$-CD/PLGA NPs with PTX concentrations equivalent to $0.125,0.25,0.5,1,2,4,8,16 \mathrm{ug} / \mathrm{mL}$ were added. Cells were incubated in a $5 \% \mathrm{CO}_{2}$ incubator at $37^{\circ} \mathrm{C}$ for 24,48 and $72 \mathrm{~h}$. MTT reagent $(100 \mu \mathrm{L}, 5 \mathrm{mg} / \mathrm{mL}$ in medium) was added for $4 \mathrm{~h}$, following the addition of MTT stop solution and the measurement of optical densities using a microplate reader (800TS Absorbance Reader, BioTek Inc).

\section{Cellular Uptake}

The human lung cancer cell line A549 was selected for assessments. The extent of internalization of the modified NPs was visualized under a fluorescence inversion microscope and quantified by flow cytometry (Cytoflex, Beckman Coulter Inc). The cellular uptake and intracellular distribution of free-Rhodamine B (free-RDM), PLGA NPs and 2-HP- $\beta$-CD/PLGA NPs in A549 cells were evaluated through assessment of the fluorescence intensity of rhodamine-B (RDM). The concentration of rhodamine-B for each formulation was fixed and unified. 
For fluorescence visualization, A549 cells were seeded onto six-well culture plates at a density of $1.7 \times 10^{5}$ cells. The medium was then replaced with fresh medium containing plain or modified PLGA NPs for $2 \mathrm{~h}$. Cells were then washed three times with cold PBS to terminate cell uptake and cells were fixed with $4 \%$ para-formaldehyde for $15 \mathrm{~min}$. Cell nuclei were stained with 4',6'-diamidino-2-phenylindole (DAPI) for 5 min followed by washing with PBS $(3 \times 5$ min washes) to remove free DAPI. Cells were visualized on a fluorescence inversion microscope.

Flow cytometry was performed to quantify the cellular uptake of NPs. A549 cells were plated in 6-well plates at a density of $\sim 50,000$ cells per well overnight and treated with free-RDM or NPs suspended in serum-free medium. Negative control groups were treated with fresh medium containing no NPs. After 1, 2 and $8 \mathrm{~h}$ of incubation, cells were collected by trypsinization and analyzed on a flow cytometer. A total of 10,000 gated events were acquired for each analysis.

\section{Pharmacokinetic Studies in Rats}

The study was approved by the Institutional Animal Care and Use Committee of Guangdong Pharmaceutical University, which ensured that the care and use of animals conformed to the National Institutes of the Health guide for the care and use of laboratory animals. Half male and half female Sprague-Dawley (SD) rats weighting 180-220 g were used for in vivo pharmacokinetic studies. Male and female rats were randomly divided into 3 groups ( 3 female and 3 male rats per group) and intravenously administered free PTX, PLGA NPs and 2-HP- $\beta$-CD/PLGA NPs at doses of $20 \mathrm{mg} /$ $\mathrm{kg}$ via the caudal vein. At $0.0833,0.25,0.5,1,2,4,8$ and 12 h post-administration, $1 \mathrm{~mL}$ of the blood samples were collected from the ophthalmic venous plexus into heparinized centrifuge tubes. Blood samples were centrifuged at $6000 \mathrm{rpm}$ for $10 \mathrm{~min}$ to separate the plasma. The obtained plasma samples were processed as follows: $100 \mu \mathrm{L}$ of which was extracted in $200 \mu \mathrm{L}$ of ethyl acetate through vortexing and ultrasonification for $1 \mathrm{~min}$. After centrifugation at $6000 \mathrm{rpm}$ for $30 \mathrm{~min}$, supernatants were collected and evaporated under nitrogen. Residues were dissolved in $100 \mu \mathrm{L}$ of methanol and used for HPLC analysis. Pharmacokinetic parameters were calculated using DAS 2.0 software (Chinese Pharmacological Society, Shanghai, China).

\section{In vivo Biodistribution}

To investigate the biodistribution of plain and 2-HP- $\beta$-CD modified NPs, Rhodamine-B (RDM)-loaded NPs were prepared by replacing PTX with RDM. The NPs were then injected into Kunming mice at doses of $20 \mathrm{mg} / \mathrm{kg}$ via the tail vein. Ex vivo imaging signals of RDM in the major organs were monitored through in vivo imaging at $5 \mathrm{~min}, 30 \mathrm{~min}, 2 \mathrm{~h}, 4 \mathrm{~h}$ and $6 \mathrm{~h}$ post-injection. After $6 \mathrm{~h}$ of administration, mice were sacrificed and the major organs (heart, liver, spleen, lung, kidney and brain) were excised. Tissues were washed three times with normal saline and placed in a surface dish for imaging.

\section{Statistical Analysis}

Data are expressed as the mean \pm standard deviation (SD) of three independent experiments. Differences amongst the groups were assessed by an analysis of variance. Intragroup group differences were assessed using an independent sample $t$-test, using SPSS software (SAS Institute, Cary, NC, USA). $P<0.05$ was considered statistically significant.

\section{Results and Discussion Fabrication of PTX-Loaded 2-HP- $\beta-C D /$ PLGA Nanoparticles}

The preparation of PTX-loaded 2-HP- $\beta$-CD/PLGA NPs is shown in Figure 1. Through ultrasonication, some of the hydrophobic segments of PLGA in the organic phase were captured by 2 -HP- $\beta-C D$ via its supramolecular effects (Process I) and owing to its hydrophilic surface coating (2-HP- $\beta-C D)$. The formerly hydrophobic segments of PLGA were reversed to hydrophilic segments and partly or entirely embedded into the outer hydrophilic nanostructure during the self-assembly of the NPs (Process II). The remaining uncoated hydrophobic PLGA segments formed an internal lipophilic nanostructure that encapsulated the PTX.

\section{Characterization of the PLGA Nanoparticles}

The size and surface properties of the NPs are the important profiles in cellular uptake and drug release processes, and in vivo pharmacokinetic and biodistribution analysis. $^{22}$ As shown in Table 2 and Figure 2, both PLGA NPs and 2-HP- $\beta$-CD/PLGA NPs had particle sizes ranging from $130 \mathrm{~nm}$ to $200 \mathrm{~nm}$, which were appropriate size ranges for their accumulation in the tumor vasculature under the influence of the EPR effect. ${ }^{4}$ Moreover, to determine the effects of the PLGA molecular weight (MW) on the characterization of NPs, PLGA and 2-HP- $\beta$-CD/PLGA NPs with an MW of $10 \mathrm{k}$, $20 \mathrm{k}$ and $30 \mathrm{k}$ were prepared and studied. As shown in Figure 2A, with an increasing MW of the PLGA, the 


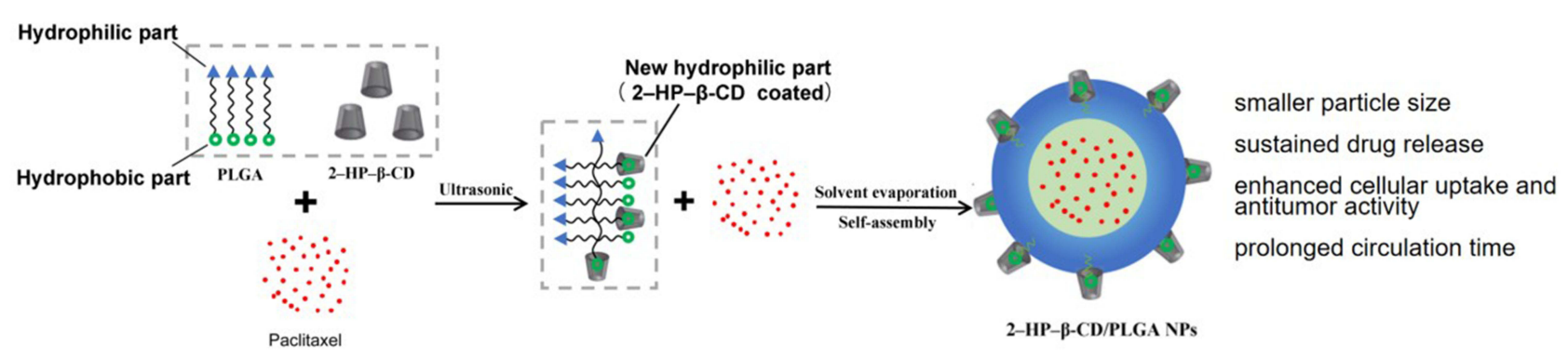

Figure I Schematic representation of 2-HP- $\beta-C D / P L G A ~ N P s$.

particle sizes of the plain PLGA NPs decreased, whilst 2 -HP- $\beta$-CD/PLGA NPs increased. Compared with the plain PLGA NPs with an MW of $10 \mathrm{k}$ and $20 \mathrm{k}$, 2-HP$\beta$-CD/PLGA NPs had smaller average particle sizes. This decreased size $(\sim 30-40 \mathrm{~nm})$ may have contributed to 2 -HP- $\beta$-CD coating that improved the hydrophilic nature of the organic solvent during NP fabrication, evidenced as a successful surface modification. Regarding NPs with an MW of $30 \mathrm{k}$, the average particle size of the 2-HP- $\beta$ $\mathrm{CD} /$ PLGA NPs were larger than those of plain PLGA NPs. This reversed result may be due to the steric effects between PLGA and 2-HP- $\beta-\mathrm{CD}$ and the hydrophobic areas of large MW PLGA (30 k) that fails to bond the hydrophobic core of 2-HP- $\beta$-CD. As such, 2-HP- $\beta-C D$ may only partially embed in the outer structure of the NPs or combine with the NPs through peripheral hydrogen bonding, resulting in an increased particle size. During the experiment, PLGA nanoparticles with different molecular weight and the same copolymerization ratio were prepared. The results showed that the hydrophilicity of PLGA nanoparticles decreased and the D90 value of PLGA nanoparticles increased with the increase of copolymerization ratio. When the copolymerization ratio is $50 / 50$ and $75 / 25$, the molecular weight of the uncoated nanoparticles increases, but the particle size becomes smaller. This may be due to the strong hydrophilicity of glycolide, and the molecular chain can be extended in the aqueous phase. With the increase of molecular weight, the molecular chain entangles with each other, but the particle size decreases. When the copolymerization ratio of PLGA is $90 / 10$, the change of particle size is not obvious with the increase of molecular weight. The copolymerization ratio of PLGA is large, the hydrophilicity is weakened, and the molecular chains cannot extend freely in the aqueous phase, so the change of particle size is not obvious with the increase of molecular weight.

As shown in Table 2 and Figure 2B, plain and modified NPs with an MW of $20 \mathrm{k}$ showed similar zeta potentials (ZP). The ZP of 2-HP- $\beta$-CD/PLGA NPs with an MW of $10 \mathrm{k}$ and $30 \mathrm{k}$ were significantly higher than those of PLGA NPs $(p<0.05)$. As a result of the negative charge of NPs, unwanted clearance through the reticuloendothelial system (RES) could be reduced. ${ }^{1-3}$

As shown in Table 2 and Figures $2 \mathrm{C}, 2-\mathrm{HP}-\beta-\mathrm{CD}$ significantly enhanced the encapsulation efficiency (EE \%) of PLGA NPs at all three surveyed MWs (10 k, $20 \mathrm{k}$ and $30 \mathrm{k}$ ). The mean EE\% of the 2-HP- $\beta$-CD/PLGA NPs (MW=10 k) was $48.94 \%$ higher than the plain PLGA NPs $(p<0.05)$. This result may be due to the additional amounts of PTX captured by the lipophilic cavity of 2-HP- $\beta-\mathrm{CD}$.

As shown in Figure $3 \mathrm{~A}$ and $\mathrm{D}$, compared with the plain PLGA NPs, the appearance of 2-HP- $\beta$-CD/PLGA NPs were more transparent. TEM was used to assess the NP surface morphology, revealing the NPs as spherical under $\mathrm{x} 3000$ magnification (Figure 3B and E). Moreover, under x 50,000 magnification, a rough particle surface could be observed on the PLGA NPs (Figure 3C), which may have formed through the absorbance of PTX onto PLGA. As shown in Figure 3F, compared with plain PLGA NPs, 2-HP- $\beta$-CD/PLGA NPs

Table 2 Characteristics of the PTX-Loaded PLGA NPs (MW=10 k)

\begin{tabular}{|l|c|c|c|c|}
\hline Samples & Particle Size (nm) & PDI & Zeta Potential (mV) & Entrapment Efficiency (\%) \\
\hline PTX-loaded PLGA NPs & $197.27 \pm 7.09$ & $0.14 \pm$ & $-25.67 \pm 7.6$ & $40.08 \pm 1.42$ \\
PTX-loaded 2-HP-B-CD/PLGA NPs ${ }^{a}$ & $151.67 \pm 5.42$ & $0.15 \pm$ & $-12.24 \pm 1.72$ & $89.02 \pm 1.72$ \\
\hline
\end{tabular}

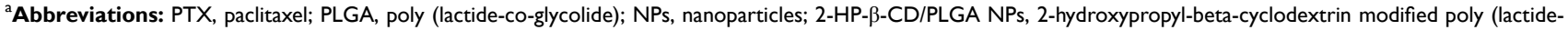
co-glycolide); PDI, polydispersity index. 
A

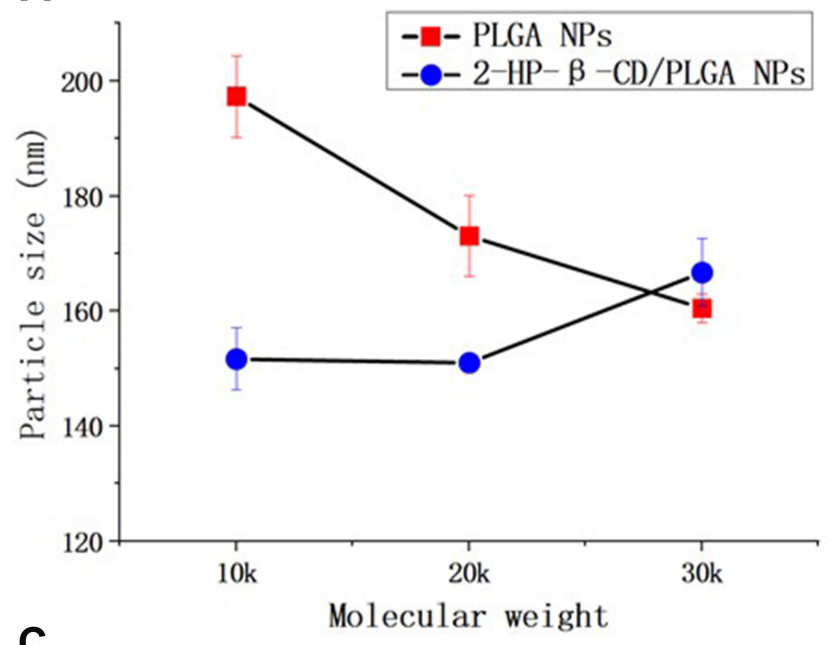

C

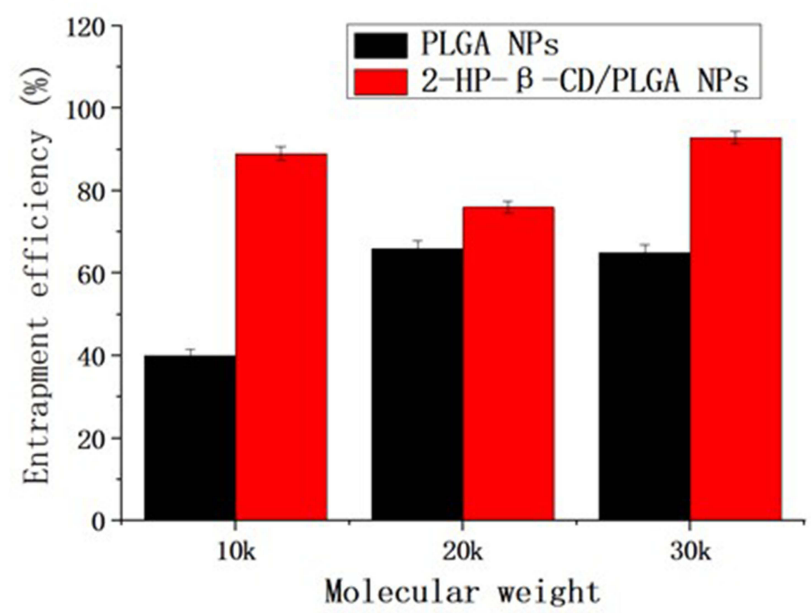

B

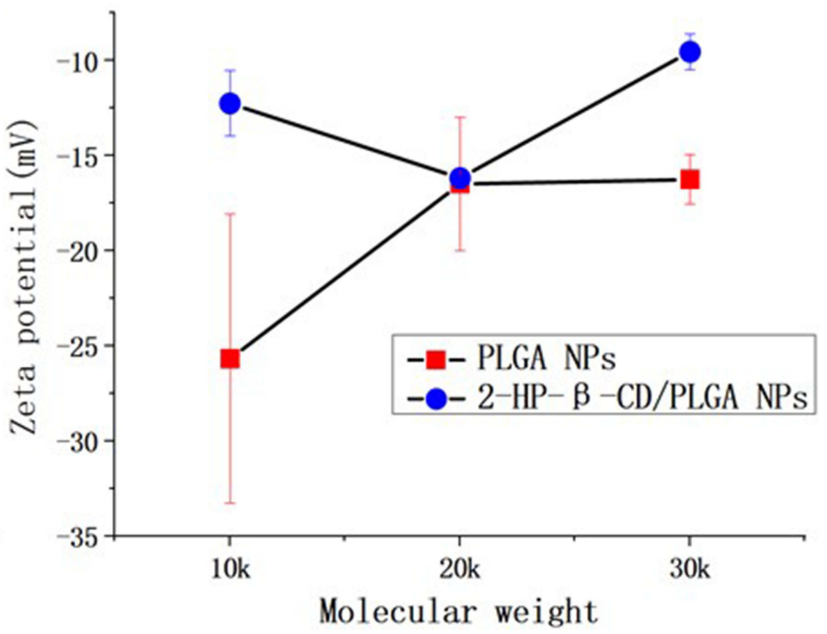

Figure 2 The effect of PLGA molecular weight on particle characteristics. (A) particle size, (B) zeta potential and (C) entrapment efficiency. Data are expressed as the means \pm standard deviations $(n=3)$.

Abbreviations: PLGA NPs, poly(lactide-co-glycolide) nanoparticles; 2-HP- $\beta$ - CD/PLGA NPs, 2-hydroxypropyl-beta-cyclodextrin modified poly(lactide-co-glycolide) nanoparticles.

were round in shape, uniform in size, and possessed a layer of translucent material around the NP core. This highlighted that surface modification using 2-HP- $\beta-\mathrm{CD}$ can improve the smoothness of the NP surface and reduce particle size.

The phase purity of the incorporated components and nanoparticle of the prepared samples were examined using XRD analytical technique (Figure 4). The X-ray powder diffractograms of pure PTX exhibited a series of intense sharp peaks, indicating its crystalline character. As shown in Figure 4, no PTX crystal peaks were present in either PLGA NPs or 2-HP- $\beta-C D / P L G A$ NPs. These data demonstrated that PTX exists in an amorphous state in both the plain and modified NPs.

The successful encapsulation of PTX and 2-HP- $\beta-C D$ modifications was further confirmed through FT-IR absorption spectra. According to Figure 5, PTX was characterized by bands of $\sim 1450 \mathrm{~cm}^{-1}, 1714.4-1733.8 \mathrm{~cm}^{-1}$ and $1646.4 \mathrm{~cm}^{-1}$, corresponding to the benzene ring, ketone carbonyl and amide carbonyl, respectively. The spectra of 2-HP- $\beta$-CD were characterized by bands of 3600 $3200 \mathrm{~cm}^{-1}$ due to hydroxyl stretching vibrations. In physical mixtures of PLGA NPs and 2-HP- $\beta$-CD/PLGA NPs, the spectra obtained were akin to the superimposition of the individual spectra of PTX, PLGA and 2-HP- $\beta-C D$. However, in the 2-HP- $\beta-\mathrm{CD} / \mathrm{PLGA}$ and PLGA NP spectra, the characteristic absorption peaks of PTX disappeared, indicating that the PTX had been successfully encapsulated by PLGA, and that the unencapsulated PTX was mostly removed through centrifugation. Moreover, compared with the plain PLGA NPs, the spectra of $2-\mathrm{HP}-\beta-\mathrm{CD} / \mathrm{PLGA}$ NP 

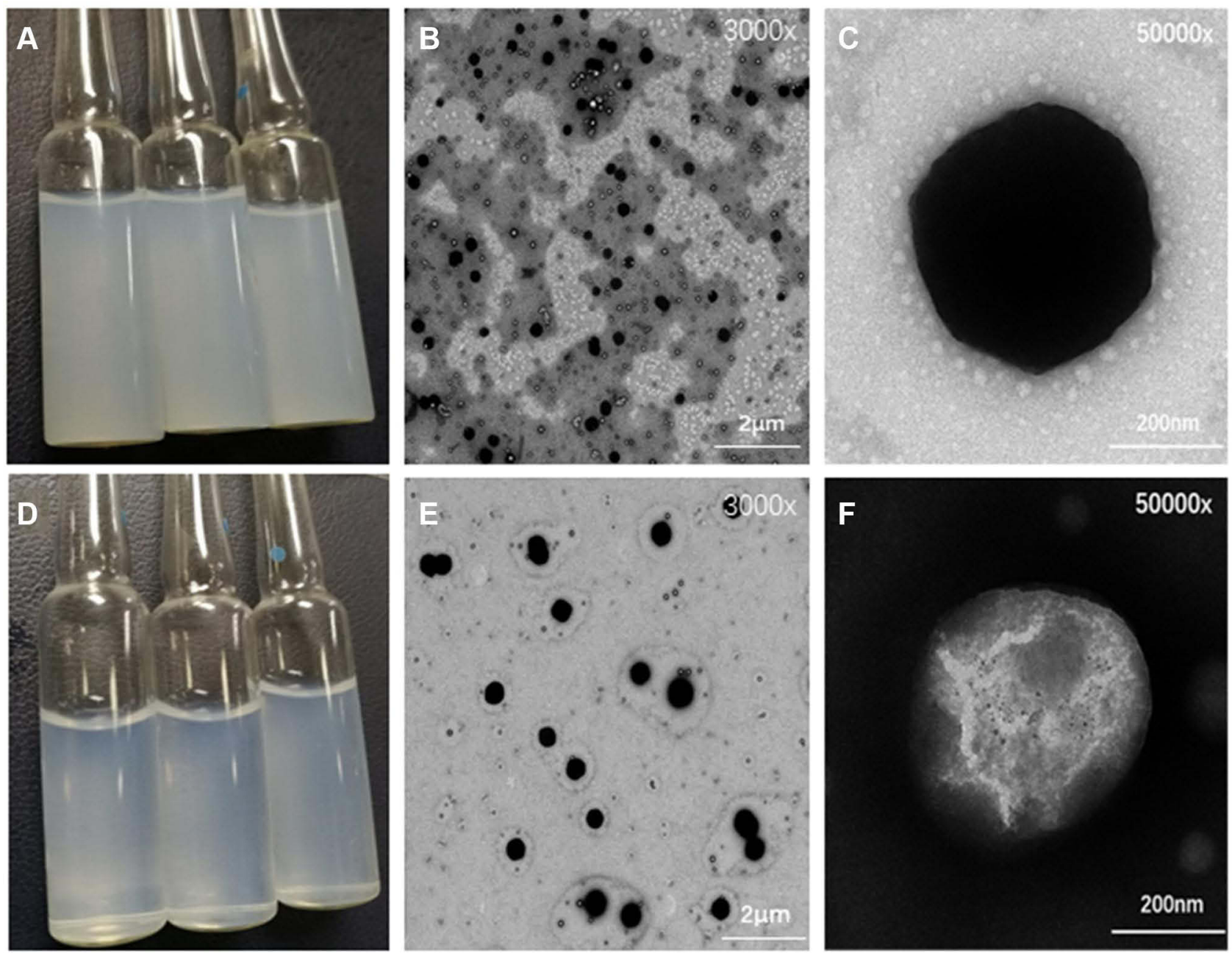

Figure 3 Morphology of NPs observed under transmission electron microscopy. (A) Appearance of PLGA NPs; (B) PLGA NPs TEM×12,000; (C) PLGA NPs TEM $\times 50,000$; (D) Appearance of 2-HP- $\beta$ - CD/PLGA NPs; (E) 2-HP- $\beta$ - CD/PLGA NPs TEM×12,000; (F) 2-HP- $\beta$ - CD/PLGA NPs TEM×50,000.

Abbreviations: TEM, transmission electron microscopy; PLGA NPs, poly(lactide-co-glycolide) nanoparticles; 2-HP- $\beta$ - CD/PLGA NPs, 2-hydroxypropyl-beta-cyclodextrin modified poly(lactide-co-glycolide) nanoparticles.

showed a broad absorbance between 3600 and $3250 \mathrm{~cm}^{-1}$, which corresponded to the stretching vibrations of the hydroxyl (-OH) of 2-HP- $\beta-\mathrm{CD}$.

In summary, the decrease in particle size and change of zeta potential, morphology, XRD spectra and FT-IR absorption spectra, suggested that the NPs modified with 2-HP- $\beta$ CD were successfully prepared. Since both plain and modified NPs with an MW of $10 \mathrm{k}$ showed the most significant differences in particle size, ZP and EE\%, they were selected for analysis in subsequent experiments.

\section{In vitro Drug Release Profiles}

The controllable drug release of the NPs and their $\mathrm{pH}$ dependency were investigated at $37 \pm 1{ }^{\circ} \mathrm{C}$ in $2 \% \mathrm{SDS}(\mathrm{pH} 7.4,6.4$, and 5.0). As shown in Figure 6A, compared with the plain
PLGA NPs, 2-HP- $\beta$-CD modified NPs exhibited smoother release curves and showed more sustained release characteristics at $\mathrm{pH}$ 7.4. The release rates of the plain NPs were $\sim 2$-fold faster than those of 2-HP- $\beta$-CD/PLGA NPs during the initial $12 \mathrm{~h}(p<0.05)$. It is likely that at $\mathrm{pH} 7.4$, PTX was released from the PLGA matrix and bound to the outer 2-HP$\beta$-CD shells. ${ }^{9}$ The binding was likely mediated by interactions between PTX and the hydrophilic hydroxyls and hydrophobic segments of 2-HP- $\beta-C D$ in the outer layer of the NPs. In addition, owing to the surface modifications of 2-HP- $\beta$ $\mathrm{CD}$, the initial burst release of the NPs were reduced at all of the three surveyed $\mathrm{pH}$ conditions, with the total drug release of plain NPs at $72 \mathrm{~h}$ typically higher than that of 2-HP- $\beta-\mathrm{CD}$ modified NPs. This may also prove the delay effects and drug control release capability of $2-\mathrm{HP}-\beta-\mathrm{CD}$ modified NPs. 


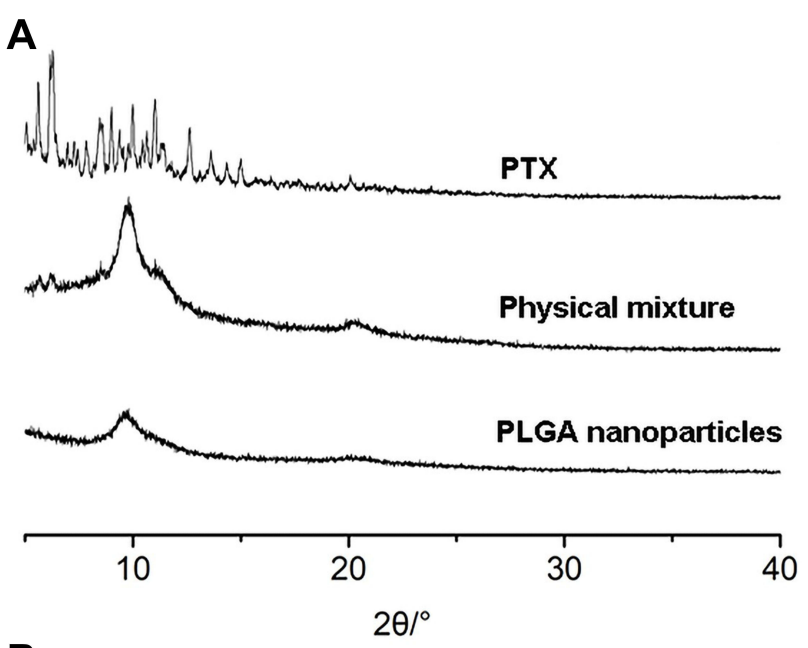

B

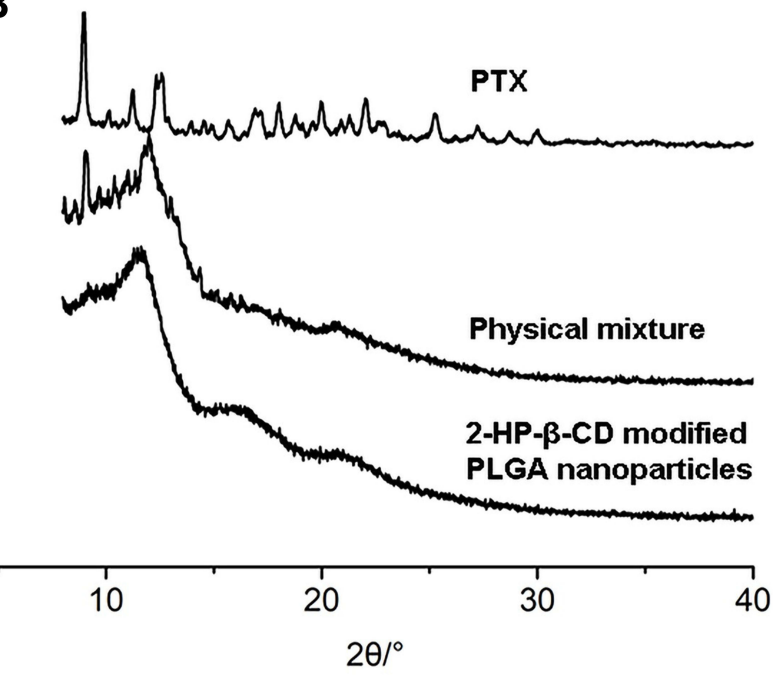

Figure 4 X-ray diffraction pattern of PLGA nanoparticles and 2-HP- $\beta$-CD/PLGA nanoparticles. (A) PLGA NPs; (B) 2-HP- $\beta$ - CD/PLGA NPs.

Abbreviations: PLGA NPs, poly(lactide-co-glycolide) nanoparticles; $2-\mathrm{HP}-\beta-\mathrm{CD} /$ PLGA NPs, 2-hydroxypropyl-beta-cyclodextrin modified poly(lactide-co-glycolide) nanoparticles.

Moreover, as shown in Figure 6B and $\mathrm{C}$ at $\mathrm{pH} 6.8$ and 5.0, the drug release profiles of 2-HP- $\beta$-CD/PLGA NPs were notably faster than those of $\mathrm{pH} 7.4(p<0.05)$ indicating excellent $\mathrm{pH}-$ responsive properties for tumor delivery.

\section{In vitro Cytotoxicity}

To evaluate the in vitro antitumor activity of the NPs, MTT assays were performed through the treatment of A549 cells with free PTX, PLGA NP and 2-HP- $\beta-C D /$ PLGA NP suspensions at a series of concentrations (Figure 7). All tested preparations exhibited an obvious dose-dependent trend at both $24 \mathrm{~h}$ and $72 \mathrm{~h}$ post-treatment. Cell growth was more significantly suppressed at
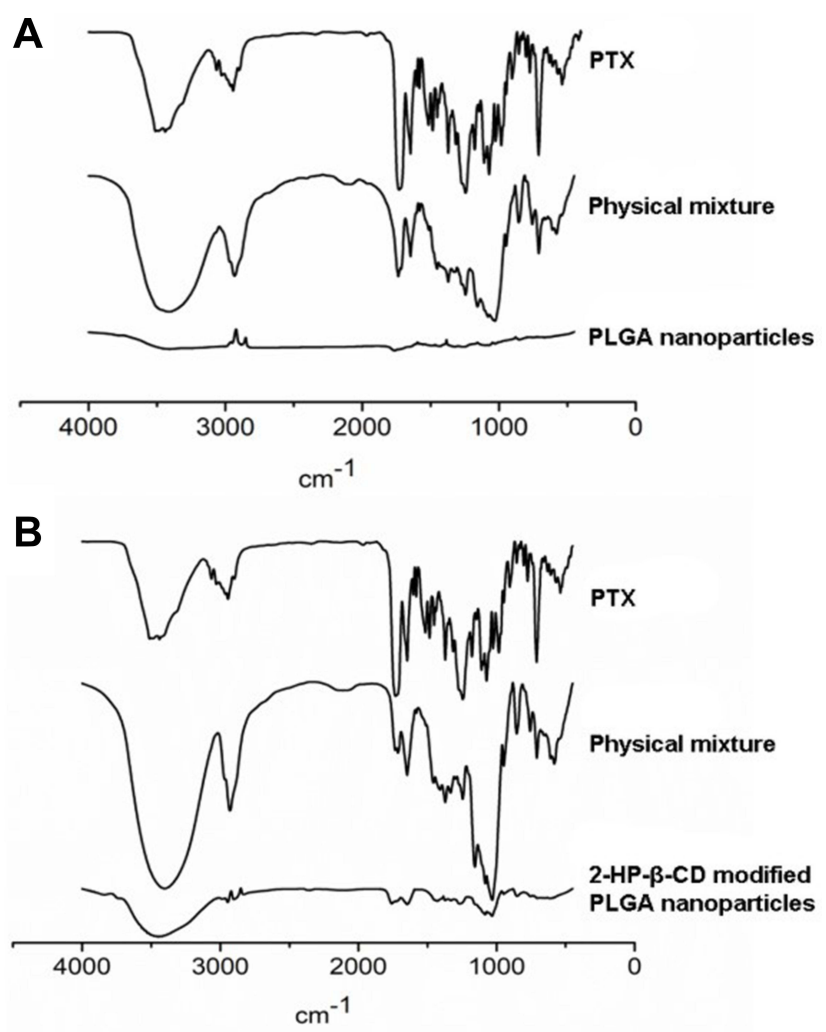

Figure 5 Infrared spectrogram of PLGA nanoparticles and 2-HP- $\beta-C D / P L G A$ nanoparticles (A) PLGA NPs; (B) 2-HP- $\beta$ - CD/PLGA NPs.

Abbreviations: PTX, paclitaxel; PLGA NPs, poly(lactide-co-glycolide) nanoparticles; 2-HP- $\beta$-CD/PLGA NPs, 2-hydroxypropyl-beta-cyclodextrin modified nanoparticles.

$72 \mathrm{~h}$ treatment than that of $24 \mathrm{~h}$. Moreover, free PTX groups exhibited the strongest toxicity at $24 \mathrm{~h}$, which may have been due to the direct contact between PTX and A549 cells as opposed to the slow release from NPs. Interestingly, although both plain and modified PLGA NPs exhibited similar cytotoxicity after $24 \mathrm{~h}$ of treatment, cell growth was more extensively suppressed by the modified NPs as opposed to free PTX at relatively higher concentrations $(\geq 1 \mu \mathrm{g} / \mathrm{mL})$ in $72 \mathrm{~h}$ treatment. The cytotoxic mechanisms of the drugs are complex, and are related to drug release from the NPs and the cellular uptake efficiency of NPs or released drugs. In this study, the prepared NPs showed a relatively sustained drug-release rate. At lower doses $(\leq 0.5 \mu \mathrm{g} / \mathrm{mL})$, the NPs exhibited lower cytotoxicity than free PTX. However, the cytotoxicity disparity between free PTX and NPs was narrow at higher doses, with the cytotoxicity of 2-HP- $\beta$ CD modified NPs surpassing that of free PTX after $72 \mathrm{~h}$ of treatment. It is likely that the 2-HP- $\beta-C D$ embedded nanostructure and the appropriate particle size 

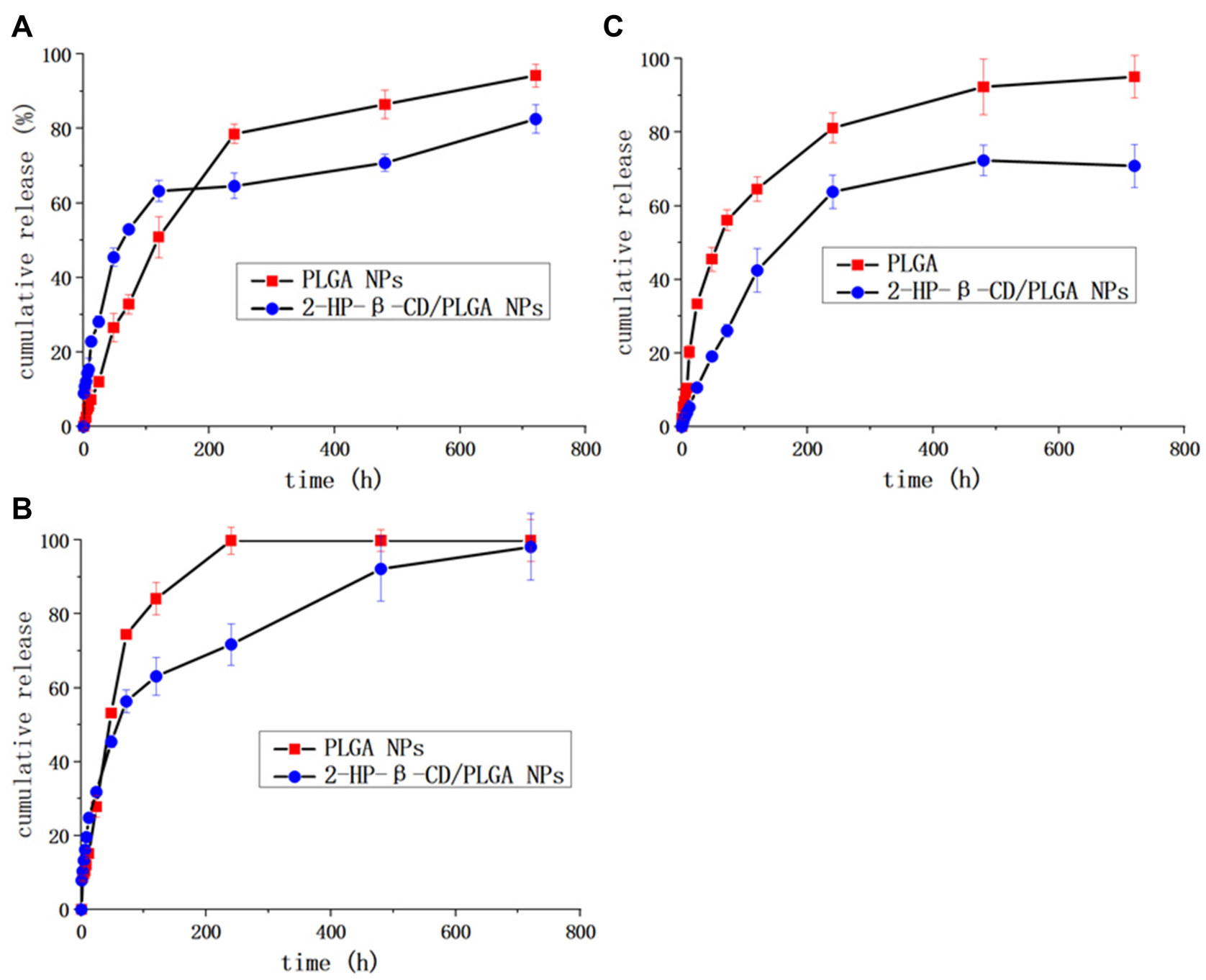

Figure 6 In vitro drug release profiles of $2-\mathrm{HP}-\beta-\mathrm{CD}$ modified NPs and naked PLGA NPs. $(\mathbf{A}) \mathrm{pH}=7.4 ;(\mathbf{B}) \mathrm{pH}=6.8 ;(\mathbf{C}) \mathrm{pH}=5.0$. Data are expressed as the means \pm standard deviations $(n=3)$.

Abbreviations: PLGA NPs, poly(lactide-co-glycolide) nanoparticles; 2-HP- $\beta$-CD/PLGA NPs, 2-hydroxypropyl-beta-cyclodextrin modified nanoparticles.

of 2-HP- $\beta$-CD/PLGA NPs increased their cellular uptake efficiency, resulting in higher levels of cytotoxicity after $72 \mathrm{~h}$ of treatment. ${ }^{23}$ These findings were further assessed in cellular uptake studies.

\section{Cellular Uptake Study}

To examine the effects of 2-HP- $\beta-\mathrm{CD}$ coating on the cellular uptake of NPs, fluorescently labeled PLGA and 2-HP- $\beta-\mathrm{CD} /$ PLGA NPs were incubated with A549 cells for $2 \mathrm{~h}$ and imaged on a fluorescence inversion microscope. Since both plain and modified NPs were based on PLGA cores, the initial levels of fluorescence were comparable across the NPs. As shown in Figure 8A, 2-HP- $\beta$-CD/PLGA NPs showed higher levels of cellular uptake than plain NPs, which was likely due to the latent reactivity of $2-\mathrm{HP}-\beta-\mathrm{CD}$ with the plasma membrane or the smaller size of the modified NPs.

These observations were further confirmed by quantitative analysis using flow cytometry. Considering the sustained release profile of 2-HP- $\beta$-CD/PLGA NPs which may lead to a latent time-dependent cellular uptake effect, cells were treated with free-RDM, plain PLGA NPs, and modified NPs for 1, 2 and $8 \mathrm{~h}$. As shown in Figure 8B, cells incubated with free-RDM showed the highest fluorescence intensity after 1, 2 and $8 \mathrm{~h}$ of incubation, whilst plain and modified PLGA NPs exhibited similar fluorescence intensities after 1 and $2 \mathrm{~h}$ of incubation. However, after $8 \mathrm{~h}$, cells treated with 2-HP- $\beta$-CD/PLGA NPs showed the highest fluorescence intensity $(p<0.05)$, confirming the additional 

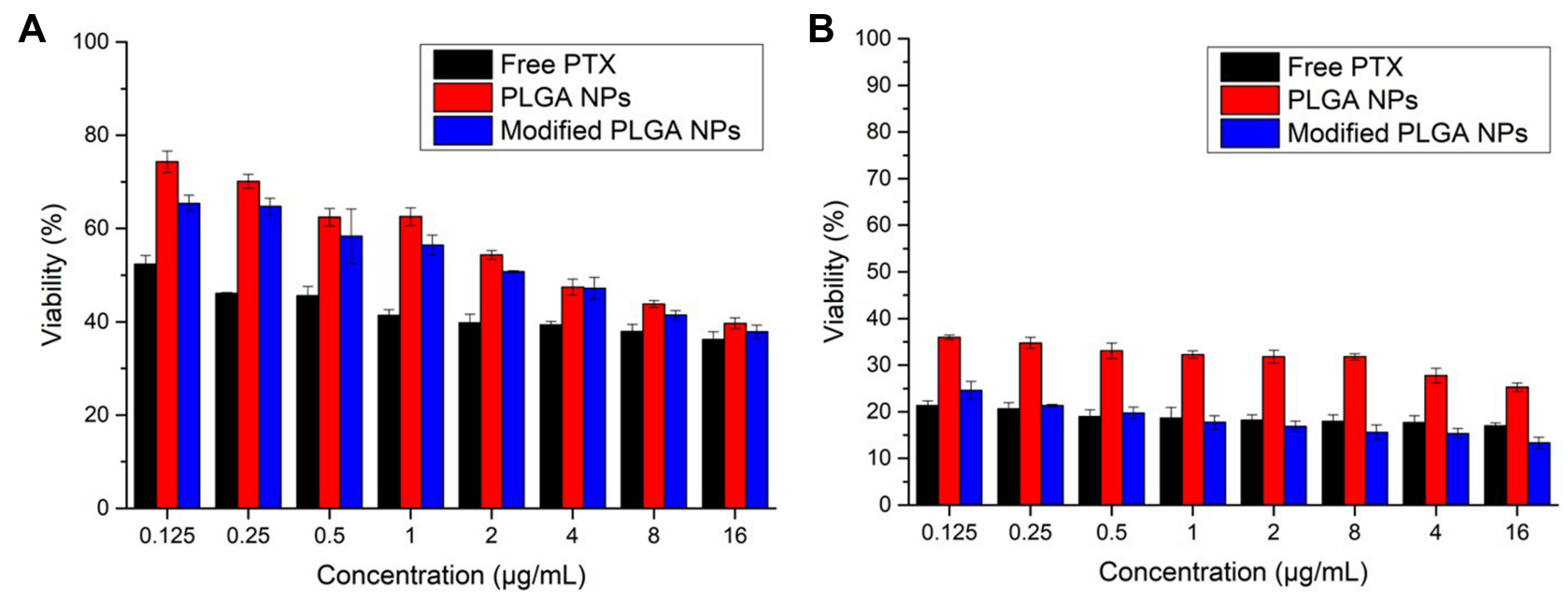

Figure 7 Viability of A549 cells cultured with free-PTX, PLGA NPs and 2-HP- $\beta$-CD/PLGA NPs for $24 \mathrm{~h}(\mathbf{A})$ and $72 \mathrm{~h}(\mathbf{B})$. Data are expressed as the means \pm standard deviations $(n=3)$.

Abbreviations: PTX, paclitaxel; PLGA NPs, poly(lactide-co-glycolide) nanoparticles; 2 -HP- $\beta$-CD/PLGA NPs, 2-hydroxypropyl-beta-cyclodextrin modified poly(lactide-coglycolide) nanoparticles.
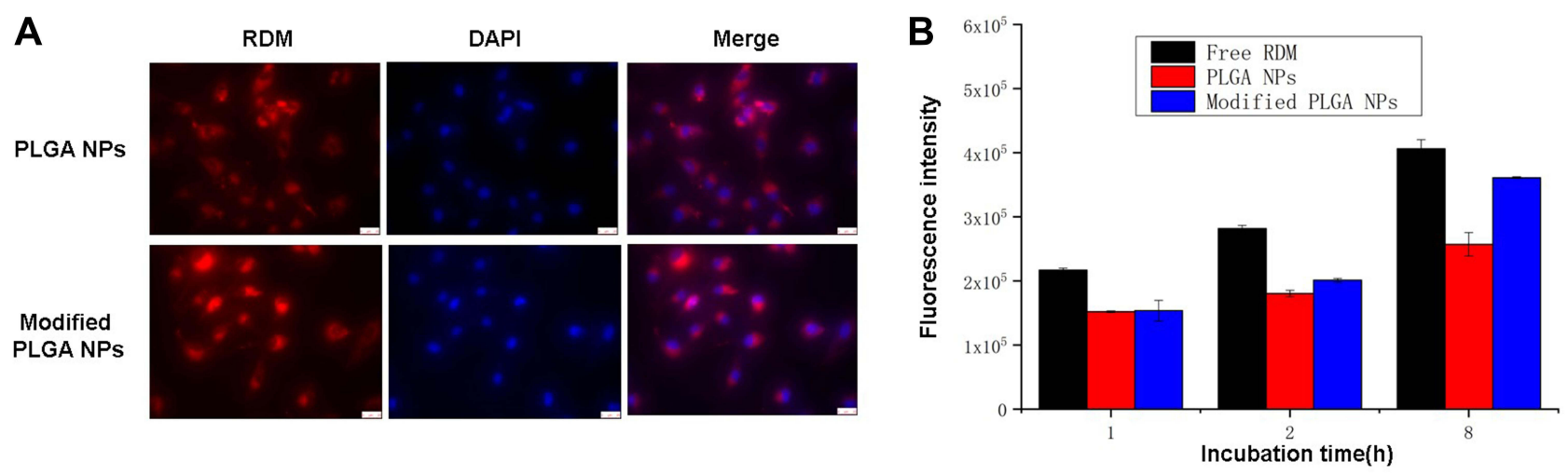

Figure 8 Biodistribution profiles of Rhodamine-B loaded NPs. (A)Fluorescence inversion microscope system images of A549 cells after incubation with naked PLGA NPs and 2-HP- $\beta$-CD modified PLGA NPs for $2 \mathrm{~h}$. (B) Flow cytometry fluorescence intensity of free Rhodamine-B (free-RDM) and Rhodamine-B loaded NPs incubated with A549 cells after $\mathrm{l}, 2 \mathrm{~h}$ and $8 \mathrm{~h}$ incubation. Data are expressed as the means \pm standard deviations $(n=3)$.

Abbreviations: RDM, Rhodamine-B; DAPI, 4',6-diamidino-2-phenylindole; PLGA NPs, fluorescence-labeled poly(lactide-co-glycolide) nanoparticles; Modified PLGA NPs, fluorescence-labeled 2-hydroxypropyl-beta-cyclodextrin modified poly(lactide-co-glycolide) nanoparticles.

contribution of $2-\mathrm{HP}-\beta-\mathrm{CD}$. This corroborated the cytotoxicity data described above.

\section{Pharmacokinetic Studies in Rats}

The pharmacokinetic profiles of the NPs are shown in Figure 9, and relevant parameters are listed in Table 3. As predicted, both plain and modified NPs exhibited higher AUC values (1.4 and 2.4-fold higher, respectively) and greater circulating effects than free paclitaxel (free PTX). As shown in Table 3, free PTX showed the highest $\mathrm{t}_{1 / 2 \alpha}$ values $(0.41 \pm 0.04 \mathrm{~h})$ whilst plain and modified NPs were similar $(0.21 \pm 0.03$ and $0.29 \pm$ $0.01 \mathrm{~h}$, respectively). However, free PTX was rapidly eliminated and decreased to $0.055 \mu \mathrm{g} / \mathrm{mL}$ within $6 \mathrm{~h}$ of injection, leading to relatively lower $t_{1 / 2 \beta}$ values. These results may be due to the fact that free PTX can be rapidly transferred by glycoproteins and eventually metabolized by CYP3A enzymes, resulting in a fast decrease in blood concentrations. ${ }^{24}$ In addition, due to the EPR effect and hydrophilic surface characteristics, the NPs could more easily accumulate in various tissues or organs. ${ }^{25,26}$ Consequently, the in vivo circulating time of the NPs were significantly prolonged than that of free PTX, resulting in higher $t_{1 / 2 \beta}$ and AUC values. Moreover, these profiles ( $t_{1 / 2 \beta}$ and $A U C$ value) of $2-\mathrm{HP}-\beta-\mathrm{CD} / \mathrm{PLGA}$ NPs were significantly higher than those of the plain NPs (3.4 and 1.7-fold increase, respectively, $p<0.05$ ). As shown in Figure 9, the blood concentrations of 


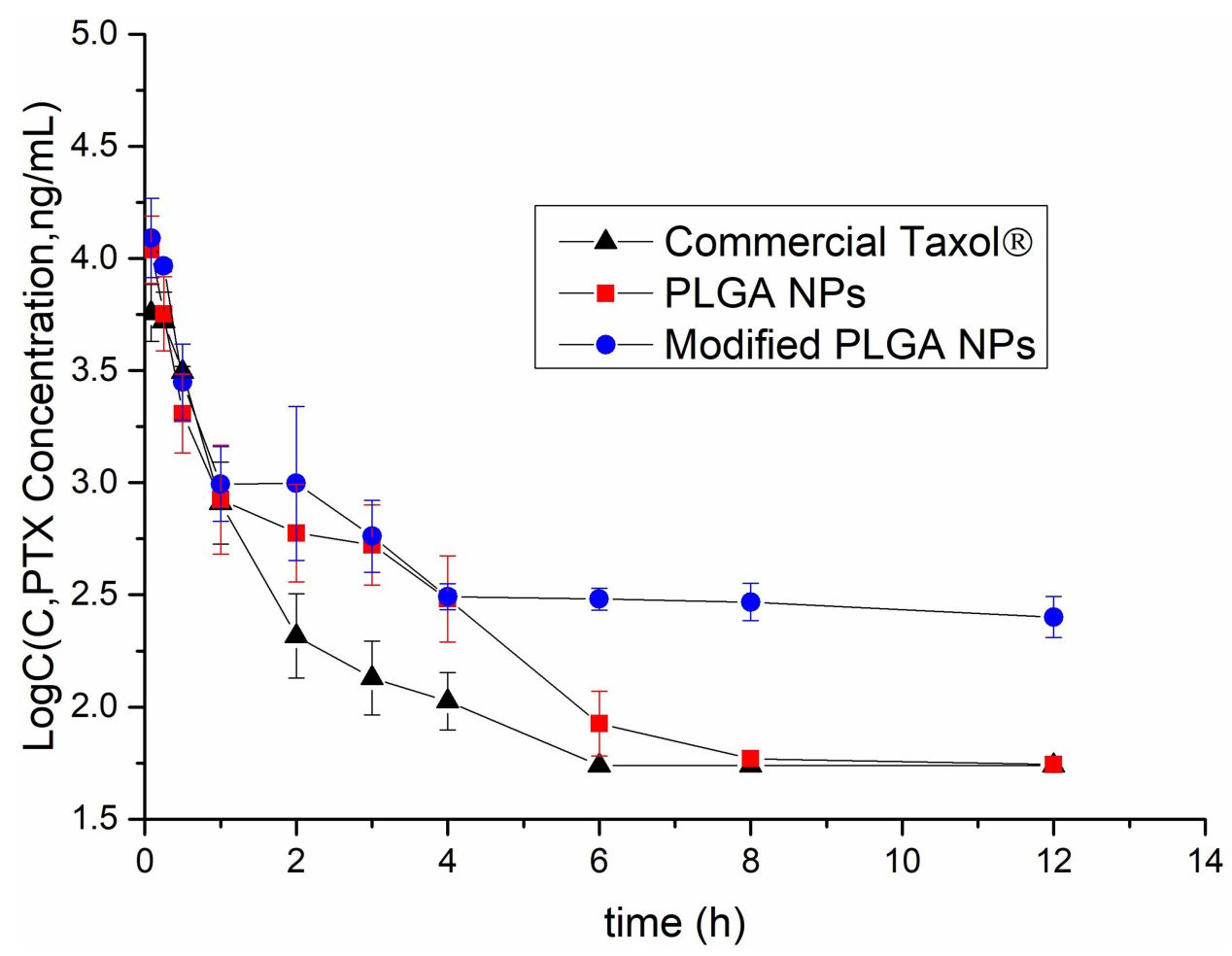

Figure 9 Pharmacokinetic profiles after an intravenous injection to Sprague-Dawley rats at the dose of $20 \mathrm{mg}^{\mathrm{kg}^{-1}}$. Data are expressed as the means \pm standard deviations ( $\mathrm{n}=6$ ) Abbreviations: PTX, paclitaxel; Commercial Taxol ${ }^{\circledR}$, commercial paclitaxel injection; PLGA NPs, poly(lactide-co-glycolide) nanoparticles; 2-HP- $\beta$-CD/PLGA NPs, 2-hydroxypropyl-beta-cyclodextrin modified poly(lactide-co-glycolide) nanoparticles.

the PLGA NPs rapidly decreased $3 \mathrm{~h}$ post-injection, and declined to $0.058 \pm 0.002 \mu \mathrm{g} / \mathrm{mL}$ within $8 \mathrm{~h}$ of injection. In comparison, 2-HP- $\beta$-CD/PLGA NPs maintained significantly higher blood concentrations $(\geq 0.252 \pm 0.032 \mu \mathrm{g} / \mathrm{mL}, p<0.05)$ at $12 \mathrm{~h}$ post-injection. It is likely that the hydrophilic surface modifications of $2-\mathrm{HP}-\beta-\mathrm{CD}$ could effectively reduce the adsorption of serum proteins and further enhance the circulating effects of $2-\mathrm{HP}-\beta-\mathrm{CD} / \mathrm{PLGA} \mathrm{NPs}$, resulting in an improved bioavailability.

\section{In vivo Biodistribution}

As shown in Figure 10A, the location of the fluorescence signal during the early stages of drug metabolism for both
NPs occurred in the liver and was determined by particle size. At $4 \mathrm{~h}$ post-injection, the NPs mainly distributed to the kidneys and bladder, and were presumably excreted by the kidneys. Both fluorescence labeled NPs rapidly distributed throughout the whole mice bodies of the mice, with 2-HP- $\beta$-CD/PLGA NPs showing higher fluorescence intensities than plain NPs within $2 \mathrm{~h}$ of injection, indicating that the modified NPs have a higher $\mathrm{C}_{\max }$ profile than plain NPs. Moreover, the fluorescence intensity of the PLGA NPs significantly decreased after $4 \mathrm{~h}$ of injection, whilst those of 2-HP- $\beta$-CD/PLGA-NPs were maintained at a relatively higher level, in agreement with the signifi-

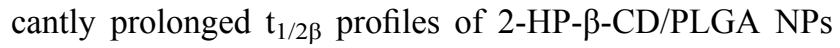

Table 3 Pharmacokinetic Profiles Following Intravenous Injection into Sprague-Dawley Rats at Doses of $20 \mathrm{Mg} / \mathrm{Kg}$

\begin{tabular}{|c|c|c|c|}
\hline Parameters & Commercial Taxol $^{\circledR}$ & PLGA NPs & Modified PLGA NPs \\
\hline $\operatorname{A\cup C}(0-t)\left(\mu g \cdot L^{-1} \cdot h^{-1}\right)^{a}$ & $4596.44 \pm 270.83$ & $6546.45 \pm 639.91$ & $11,072.20 \pm 908.74$ \\
\hline $\mathrm{t}_{1 / 2 \alpha}(\mathrm{h})$ & $0.41 \pm 0.04$ & $0.2 I \pm 0.03$ & $0.29 \pm 0.01$ \\
\hline$t_{1 / 2 \beta}(h)$ & $0.48 \pm 0.06$ & $3.81 \pm 1.47$ & $13.06 \pm 3.58$ \\
\hline MRT $(0-t)(h)$ & $0.57 \pm 0.08$ & $0.98 \pm 0.04$ & $2.38 \pm 0.12$ \\
\hline $\mathrm{Vz}\left(\mathrm{L} \cdot \mathrm{kg}^{-1}\right)$ & $3.29 \pm 0.69$ & $14.25 \pm 0.39$ & $27.22 \pm 4.54$ \\
\hline $\mathrm{C}_{\max }\left(\mathrm{ng} \cdot \mathrm{mL}^{-1}\right)$ & $5707.64 \pm 268.24$ & $10,928.19 \pm 988.67$ & $|2,338.43 \pm| 374.3 \mid$ \\
\hline
\end{tabular}

${ }^{a}$ Abbreviations: PLGA, poly(lactide-co-glycolide); NPs, nanoparticles; 2-HP- $\beta-C D, 2$-hydroxypropyl-beta-cyclodextrin; NPs, nanoparticles; AUC, area under the curve; MRT, mean residence time. 
A

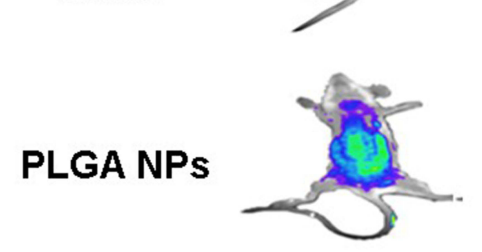

2-HP- $\beta-C D /$ PLGA NPS

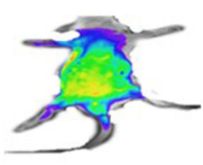

B

PLGA NPs

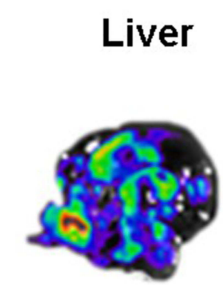

2-HP- $\beta-C D /$ PLGA NPS

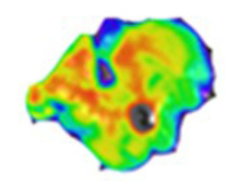

$30 \mathrm{~min}$
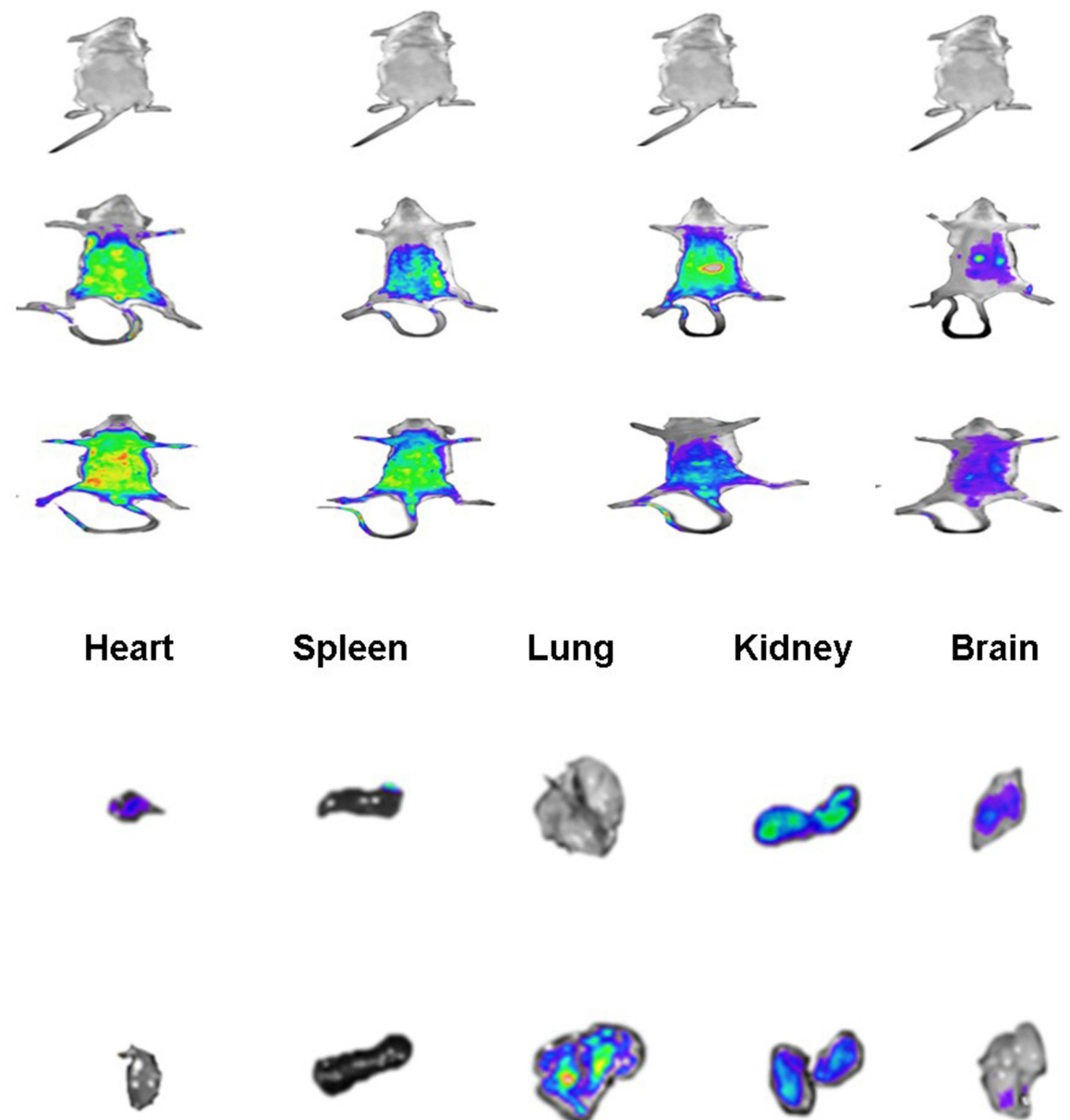

$4 \mathrm{~h}$

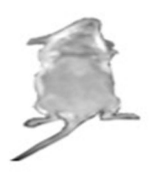

$6 \mathrm{~h}$
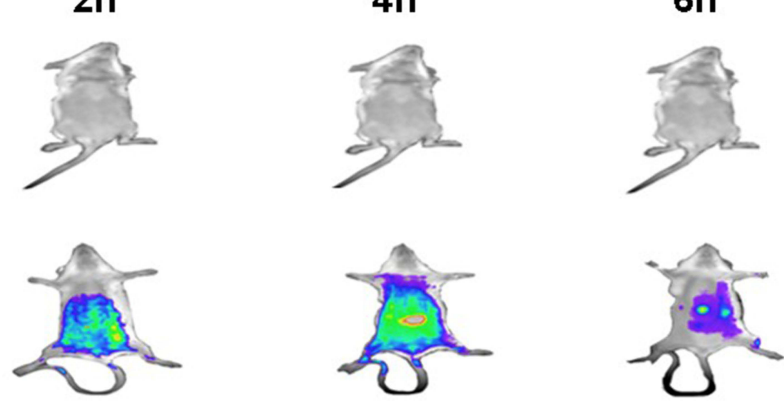

Lung

Kidney

Brain
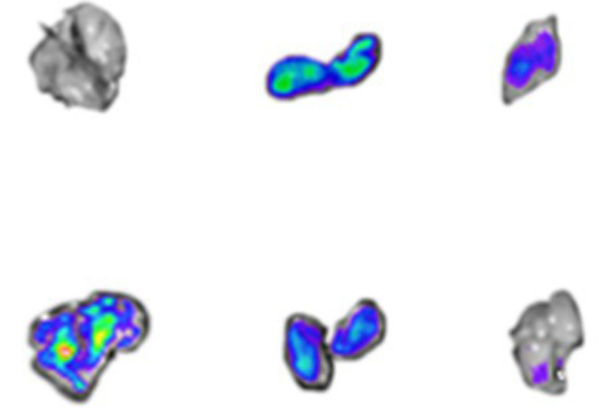

Figure 10 In vivo imaging and biodistribution analysis after tail vein injection of RDM-loaded NPs. (A) Real-time biodistribution imaging in mice. (B) In vitro visceral fluorescence imaging of mice organs after $6 \mathrm{~h}$ post-injection.

Abbreviations: RDM-loaded NPs, Rhodamine-B-loaded nanoparticles; PLGA NPs, fluorescence-labeled poly(lactide-co-glycolide) nanoparticles; Modified PLGA NPs, fluorescence-labeled 2-hydroxypropyl-beta-cyclodextrin modified poly(lactide-co-glycolide) nanoparticles.

in pharmacokinetic studies. This notably longer circulating effect of the modified NPs was attributed to the 2-HP- $\beta$ CD present in the surface of PLGA. That is, the higher proportion of hydroxyl groups on the surface of 2-HP- $\beta$ CD further enhanced the surface hydrophilicity of PLGA, thus increasing its ability to be recognized by RES, resulting in higher AUC values and excellent in vivo circulating times of the 2-HP- $\beta-\mathrm{CD} / \mathrm{PLGA}$ NPs.

In vitro visceral imaging of the mouse organs is shown in Figure 10B. The NPs concentrated in the liver after 6 $\mathrm{h}$ of injection, which may have been due to their recognized by the RES and their passive targeting to the liver. The fluorescence intensity of the 2-HP- $\beta$-CD/PLGA-NPs in liver tissue was weaker than that of plain PLGA NPs. It is likely that the modified NPs achieved "invisibility" by utilizing the hydrophilic coating of 2-HP- $\beta-C D$, avoiding the scavenging effects of the immune system, prolonging in vivo circulation times. Interestingly, at $6 \mathrm{~h}$ post-injection, the NPs showed fluorescent signals in the mouse lungs only when surface-modified with $2-\mathrm{HP}-\beta-\mathrm{CD}$, suggesting that the 2-HP- $\beta-\mathrm{CD} / \mathrm{PLGA}-\mathrm{NPs}$ can act as drug carriers the treatment of lung cancer.

\section{Conclusions}

In this study, a novel PTX-loaded biodegradable material was established using a simple and feasible method that optimized the particle profiles, drug release processes and biological behavior of the NPs. Firstly, we investigated the effects of 2-HP- $\beta-C D$ coating and the MW of PLGA on the particle size, zeta potential, and drug load efficiency of the NPs. The results showed that the PLGA MW exhibited influenced the nano-properties of the NPs, and that the 2-HP- 
$\beta$-CD-NPs differed according to MW due to steric effects. In addition, 2-HP- $\beta$-CD modifications significantly decreased the particle size and enhanced the encapsulation efficiency (EE\%). The EE\% of $2-\mathrm{HP}-\beta-\mathrm{CD} / \mathrm{PLGA}$ NPs were $49.12 \%$ higher than that of plain PLGA NPs, indicating that 2-HP- $\beta$ CD encapsulates certain levels of PTX, resulting in higher $\mathrm{EE} \%$ values. As the plain and modified NPs with an MW of $10 \mathrm{k}$ showed the most significant differences in particle size, zeta potential and $\mathrm{EE} \%$, they were selected for further assessments. The NP morphologies were confirmed by XRD and FT-IR, and the 2-HP- $\beta$-CD modification led to superior drug release profiles and higher cancer cell-specific toxicity. 2-HP- $\beta$-CD/PLGA NPs showed notable sustained-release properties at $\mathrm{pH} 7.4$ with drug release rates that were accelerated at $\mathrm{pH} 6.8$ and 5.0, considered an appropriate $\mathrm{pH}$ responsive profile for tumor treatment. MTT assays showed that the 2-HP- $\beta-C D$ surface modifications enhanced the cytotoxicity of NPs to A549 cells, likely due to their smaller particle size. These results were further confirmed in cellular uptake studies. Furthermore, pharmacokinetic analysis showed that the 2-HP- $\beta$-CD/PLGA NPs exhibited prolonged in vivo circulatory times and improved pharmacokinetic profiles than the PLGA NPs. At $6 \mathrm{~h}$ post-injection, only the modified NPs were targeted to mouse lungs, highlighting 2-HP- $\beta$-CD/PLGA-NPs as potential carriers for lung cancer treatment. On the basis of the drug release profiles reported above, we hypothesized that the combination of $2-\mathrm{HP}-\beta-\mathrm{CD}$ and PLGA was as follows: after ultrasonication, the hydrophobic segments of PLGA in the organic phase were captured by $2-\mathrm{HP}-\beta-\mathrm{CD}$ through supramolecular effects. Owing to their hydrophilic surface coating, these formerly hydrophobic segments of PLGA became hydrophilic and partly or entirely embedded in the outer hydrophilic nanostructure upon NP self-assembly. PTX was then encapsulated in the inner nanostructure of the NP composed of hydrophobic segments.

In summary, we developed a simple and efficient surface modification strategy that can alter the particle size, drug release profiles, cellular toxicity and biological fate of NPs, improving their potential as drug delivery systems for cancer therapeutics and diagnostics.

\section{Abbreviations}

PTX, paclitaxel; PLGA, poly(lactide-co-glycolide); 2-HP$\beta$-CD, 2-hydroxypropyl- $\beta$-cyclodextrin; NPs, nanoparticles; MTT, methyl thiazolyl tetrazolium assay; EE\%, encapsulation efficiency; TEM, transmission electron microscopy; FT-IR, Fourier transform infrared spectroscopy; SD rats, Sprague-Dawley rats; AUC, area under the curve; MRT, mean residence time.

\section{Acknowledgments}

Kangyu Zheng, Xiangmei Liu and Junfeng Ban are co-first authors for this study.

\section{Author Contributions}

All authors made substantial contributions to conception and design, acquisition of data, or analysis and interpretation of data; took part in drafting the article or revising it critically for important intellectual content; agreed to submit to the current journal; gave final approval of the version to be published; and agreed to be accountable for all aspects of the work.

\section{Funding}

We acknowledge the financial support from the Natural Science Foundation of Guangdong Province(Grant Number 2019A1515011018); The planned Science and Technology Project of Guangdong Province(2017B020231001); Guangdong Graduate Education Innovation Program: Project Funded by Guangdong Province Joint Training Graduate Demonstration Base (Guangzhou General Pharmaceutical Research Institute Co., Ltd.) Guangdong Pharmaceutical University "Innovation and Enhancing Project" and Guangdong “Climbing” Program for Undergraduates (2021).

\section{Disclosure}

The authors declare that they have no known competing financial interests or personal relationships that could have appeared to influence the work reported in this paper.

\section{References}

1. Sun Q, Zhou Z, Qiu N, Shen Y. Rational design of cancer nanomedicine: nanoproperty integration and synchronization. Adv Mater. 2017;29(14).

2. Ma Z, Li J, Lin K, et al. Pharmacophore hybridisation and nanoscale assembly to discover self-delivering lysosomotropic new-chemical entities for cancer therapy. Nat Commun. 2020;11(1):4615. doi:10. 1038/s41467-020-18399-4

3. Kobayashi H, Choyke PL. Super enhanced permeability and retention (SUPR) effects in tumors following near infrared photoimmunotherapy. Nanoscale. 2016;8(25):12504-12509. doi:10.1039/C5NR05552K

4. Luk BT, Zhang L. Current advances in polymer-based nanotheranostics for cancer treatment and diagnosis. ACS Appl Mater Interfaces. 2014;6(24):21859-21873. doi:10.1021/am5036225

5. Lan H, Zhang W, Jin K, Liu Y, Wang Z. Modulating barriers of tumor microenvironment through nanocarrier systems for improved cancer immunotherapy: a review of current status and future perspective. Drug Deliv. 2020;27(1):1248-1262. doi:10.1080/10717544.2020.18 09559 
6. Jain RK. Determinants of tumor blood flow: a review. Cancer Res. 1988;48(10):2641-2658.

7. Jacobetz MA, Chan DS, Neesse A, et al. Hyaluronan impairs vascular function and drug delivery in a mouse model of pancreatic cancer. Gut. 2013;62(1):112-120. doi:10.1136/gutjnl-2012-302529

8. Konerding MA, Miodonski AJ, Lametschwandtner A. Microvascular corrosion casting in the study of tumor vascularity: a review. Scanning Microsc. 1995;9(4):1233-1243, 1243-1244.

9. Kolacna L, Bakesova J, Varga F, et al. Biochemical and biophysical aspects of collagen nanostructure in the extracellular matrix. Physiol Res. 2007;56(Suppl 1):S51-S60.

10. Levental KR, Yu H, Kass L, et al. Matrix crosslinking forces tumor progression by enhancing integrin signaling. Cell. 2009;139 (5):891-906. doi:10.1016/j.cell.2009.10.027

11. Jain RK, Stylianopoulos T. Delivering nanomedicine to solid tumors. Nat Rev Clin Oncol. 2010;7(11):653-664. doi:10.1038/nrclinonc. 2010.139

12. Bouzin C, Feron O. Targeting tumor stroma and exploiting mature tumor vasculature to improve anti-cancer drug delivery. Drug Resist Updat. 2007;10(3):109-120. doi:10.1016/j.drup.2007.03.001

13. Boucher Y, Jain RK. Microvascular pressure is the principal driving force for interstitial hypertension in solid tumors: implications for vascular collapse. Cancer Res. 1992;52(18):5110-5114.

14. Schudel A, Chapman AP, Yau MK, et al. Programmable multistage drug delivery to lymph nodes. Nat Nanotechnol. 2020;15 (6):491-499. doi:10.1038/s41565-020-0679-4

15. Stylianopoulos T, Martin JD, Chauhan VP, et al. Causes, consequences, and remedies for growth-induced solid stress in murine and human tumors. Proc Natl Acad Sci U S A. 2012;109 (38):15101-15108. doi:10.1073/pnas.1213353109

16. Chen H, Zhang W, Zhu G, Xie J, Chen X. Rethinking cancer nanotheranostics. Nat Rev Mater. 2017;2(7). doi:10.1038/natrevmats. 2017.24

17. Lin J, Yin Q, Chen B, et al. A magnetism/laser-auxiliary cascaded drug delivery to pulmonary carcinoma. Acta Pharm Sin B. 2020;10 (8):1549-1562. doi:10.1016/j.apsb.2019.12.017
18. Fonseca C, Simoes S, Gaspar R. Paclitaxel-loaded PLGA nanoparticles: preparation, physicochemical characterization and in vitro anti-tumoral activity. J Control Release. 2002;83(2):273-286. doi:10. 1016/S0168-3659(02)00212-2

19. Hill LE, Taylor TM, Gomes C. Antimicrobial efficacy of poly (DL-lactide-co-glycolide) (PLGA) nanoparticles with entrapped cinnamon bark extract against Listeria monocytogenes and Salmonella typhimurium. J Food Sci. 2013;78(4):N626-N632 . doi:10.1111/17503841.12069

20. Cirpanli Y, Bilensoy E, Lale DA, Calis S. Comparative evaluation of polymeric and amphiphilic cyclodextrin nanoparticles for effective camptothecin delivery. Eur J Pharm Biopharm. 2009;73(1):82-89. doi:10.1016/j.ejpb.2009.04.013

21. Trapani G, Lopedota A, Boghetich G, et al. Encapsulation and release of the hypnotic agent zolpidem from biodegradable polymer microparticles containing hydroxypropyl-beta-cyclodextrin. Int J Pharm. 2003;268(1-2):47-57. doi:10.1016/j.ijpharm.2003.08.016

22. Ho BN, Pfeffer CM, Singh A. Update on nanotechnology-based drug delivery systems in cancer treatment. Anticancer Res. 2017;37 (11):5975-5981. doi:10.21873/anticanres.12044

23. Win KY, Feng SS. Effects of particle size and surface coating on cellular uptake of polymeric nanoparticles for oral delivery of anticancer drugs. Biomaterials. 2005;26(15):2713-2722. doi:10.1016/j. biomaterials.2004.07.050

24. Kirby SM, Anna SL, Walker LM. Effect of surfactant tail length and ionic strength on the interfacial properties of nanoparticle-surfactant complexes. Soft Matter. 2017;14(1):112-123. doi:10.1039/C7SM0 $1806 \mathrm{~A}$

25. Maeda H, Bharate GY, Daruwalla J. Polymeric drugs for efficient tumor-targeted drug delivery based on EPR-effect. Eur J Pharm Biopharm. 2009;71(3):409-419. doi:10.1016/j.ejpb.2008.11.010

26. Maeda H, Nakamura H, Fang J. The EPR effect for macromolecular drug delivery to solid tumors: improvement of tumor uptake, lowering of systemic toxicity, and distinct tumor imaging in vivo. $A d v$ Drug Deliv Rev. 2013;65(1):71-79. doi:10.1016/j.addr.2012.10.002

\section{Publish your work in this journal}

Drug Design, Development and Therapy is an international, peerreviewed open-access journal that spans the spectrum of drug design and development through to clinical applications. Clinical outcomes, patient safety, and programs for the development and effective, safe, and sustained use of medicines are a feature of the journal, which has also been accepted for indexing on PubMed Central. The manuscript management system is completely online and includes a very quick and fair peer-review system, which is all easy to use. Visit http://www. dovepress.com/testimonials.php to read real quotes from published authors. 